\title{
Boiling heat transfer during flow of distilled water in an asymmetrically heated rectangular minichannel
}

\author{
Kinga Strąk ${ }^{*}$, Magdalena Piasecka \\ Faculty of Mechatronics and Mechanical Engineering \\ Kielce University of Technology, Al. 1000-lecia P.P. 7, 25-314 Kielce, Poland
}

\begin{abstract}
This paper discusses test results concerning flow boiling heat transfer in a minichannel $1.7 \mathrm{~mm}$ in depth, $16 \mathrm{~mm}$ in width and $180 \mathrm{~mm}$ in length. The essential part of the experimental stand was a vertically oriented rectangular minichannel, which was heated asymmetrically with a plate made of Haynes-230 alloy. Distilled water was used as the cooling fluid. Changes in the temperature on the outer side of the heated plate in the central, axially symmetric part of the channel were measured using infrared thermography. Simultaneously, the other side of the heated plate in contact with the fluid was observed through a glass pane to identify the two-phase flow patterns. The one-dimensional model used for the heat transfer analysis took into account the heat flow direction, which was perpendicular to the direction of the fluid flow in the minichannel. The study involved determining local values of the heat transfer coefficient and generating boiling curves. The data for water were compared with the findings reported for the FC-72 fluid.
\end{abstract}

\section{Introduction}

Flow boiling heat transfer of water in minichannels and microchannels has been described by various researchers (see, for example, [1-2] and [3-5], respectively). Reference [1] investigates the effect of pressure (ranging from 2 to 16 bar) on the flow boiling of water. Reference [2] analyses the influence of surface wettability on the two-phase pressure drop during flow boiling of water at atmospheric pressure in a single rectangular channel $0.5 \mathrm{~mm}$ high, $5 \mathrm{~mm}$ wide and $180 \mathrm{~mm}$ long. References [3-4] deal with the flow boiling of deionised and degassed water for different mass fluxes in a vertical narrow rectangular microchannel with a hydraulic diameter of $d_{h}=0.48 \mathrm{~mm} \mathrm{[3]} \mathrm{and} d_{h}=1.2 \mathrm{~mm} \mathrm{[4].}$ A study of the flow boiling of deionized water in silicon microchannels in a single annular flow boiling regime is presented in [5].

One of the key parameters affecting flow boiling heat transfer in a mini space is the spatial orientation of the test module. Reference [6] discusses complex mechanisms of the critical heat flux (CHF) in flow boiling for different orientations of a rectangular channel (with inclination angles ranging from $0^{\circ}$ to $270^{\circ}$ ) under standard gravity conditions with heat supplied to one side or two sides of the heating foil. The influence of gravity on the CHF in flow boiling was negated in Ref. [7]. The negating criteria for two-phase inlet conditions were: to overcome the influence of gravity perpendicular to the heating wall, to overcome the influence of gravity parallel to the heating wall and to ensure that the heated wall is sufficiently long to ensure liquid contact.
Reference [8] focuses on subcooled flow boiling. The measurements of the CHF were conducted over a range of flow orientations: $0^{\circ}, 45^{\circ}, 90^{\circ}, 135^{\circ}, 180^{\circ}, 225^{\circ}, 270^{\circ}$ and $315^{\circ}$. The analysis of the measurement results reveals that the CHF increases with increasing velocity and that at the highest velocity there is a considerable consolidation of data for different orientations.

The influence of minichannel position on heat transfer coefficient and the occurrence of flow structures were investigated in the research conducted at the Kielce University of Technology [9-11]. Enhanced surfaces were used in the experiments. The use of microstructured surfaces produced in thermal processes (as described in [12-15]) is known to intensify the heat transfer process. Studies have been conducted on pool boiling [16-20], flow boiling [9-11, 21-23] heat transfer and confined spaces as face seals [24-25].

\section{Experimental stand and methodology}

\subsection{Experimental set-up}

The major parts of the experimental setup presented in Fig. 1 were: a main loop, a supply and control system and a data and image acquisition system. The flow loop comprised a test section (1), a gear pump (2), a compensating tank (3), a heat exchanger (4), a filter (5), a mass flow meter (6), a deaerator (7) and pressure converters (8). The data and image acquisition system was made up of an infrared camera (17), a quick shot camera (9), a lighting system (10), a data acquisition

Corresponding author: kzietala@tu.kielce.pl 
station (11) and a computer with specialized software (12). The supply and control system consisted of an inverter welder (13), a shunt (14), an ammeter (15) and a voltmeter (16).

The test module (Fig. 2a) with a rectangular minichannel, $1.7 \mathrm{~mm}$ in depth, $16 \mathrm{~mm}$ in width and $180 \mathrm{~mm}$ in length, was the most important element of the experimental setup. As shown in Fig. 2b, different orientations of the minichannel at different inclination angles were analysed.

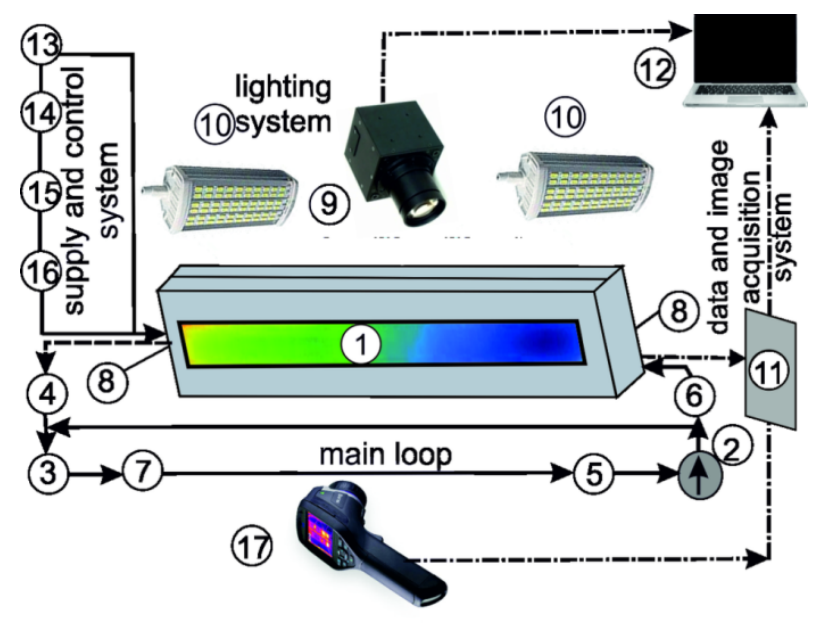

Fig. 1. The main systems of the experimental setup, 1-test section with a minichannel; 2- gear pump, 3-compensating tank/pressure regulator, 4-tube-type heat exchanger, 5-filter, 6-mass flowmeter, 7-deaerator, 8-pressure converter, 9-quick shot camera, 10-high power LEDs (400 W), 11-data acquisition station, 12-personal computer (PC), 13-inverter welder, 14-shunt, 15-ammeter, 16-voltmeter, 17-infrared camera.

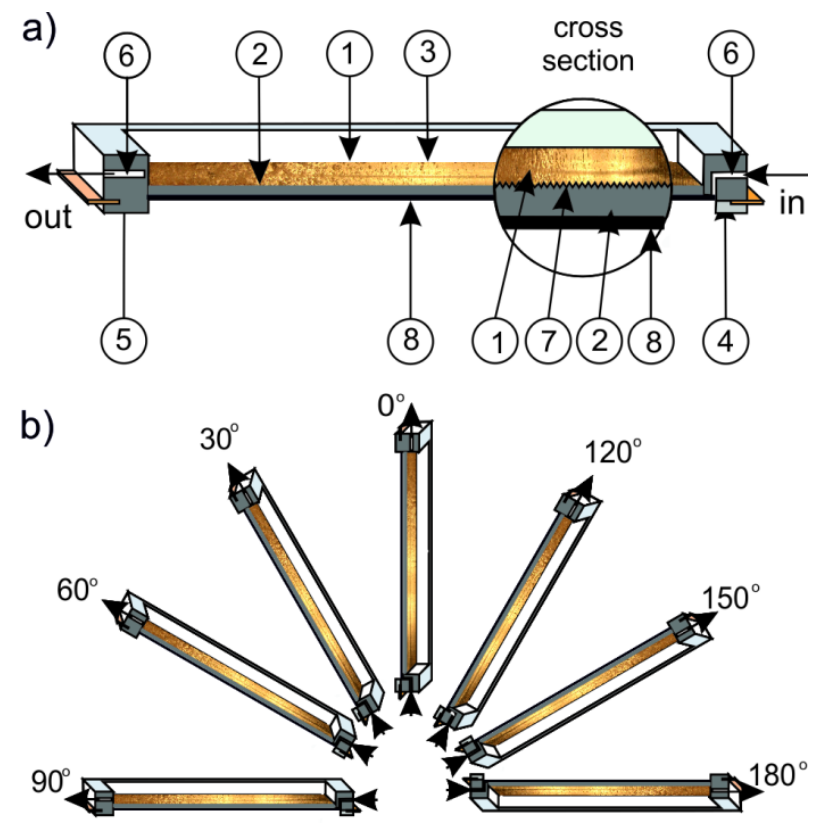

Fig. 2. a) The test module with the minichannel:

1-minichannel, 2-heated plate, 3-glass panel, 4-channel body, 5-front cover, 6-thermocouple, 7-enhanced surface of the plate, 8 -black paint layer, b) orientations of the test module.

The surface of the $0.45 \mathrm{~mm}$ thick heated plate made of Haynes-230 alloy was modified on one side.
The cooling fluid flowing in the minichannel was distilled water. Infrared thermography was employed to measure changes in the temperature on the outer smooth side of the plate. It was necessary to coat the surface with a black paint to obtain an emissivity of 0.83 [21].

The temperature measurements were limited to the central axially symmetric part of the minichannel (4 mm x $180 \mathrm{~mm}$ ). On both sides of the minichannel there were narrow micanite reinforcement panels to prevent the heated plate from deforming.

The other side of the plate, i.e. the modified surface in contact with the fluid was observed through a glass pane. The surface was illuminated by high power LEDs. The two-phase flow patterns were recorded using a quick shot camera. The surface enhanced by vibration-assisted laser surface texturing had a roughness parameter $R a=1.46 \mu \mathrm{m}$.

K-type thermocouples and pressure converters were installed at the inlet and outlet of the minichannel. The E60 FLIR infrared camera had an accuracy of $\pm 1{ }^{\circ} \mathrm{C}$ or $\pm 1 \%$ in the temperature range $0 \div 120^{\circ} \mathrm{C}$.

\subsection{Methodology}

The tests involved deaerating the distilled water before it flowed laminarly along the minichannel. The system operated at a predetermined pressure and a predetermined flow rate. As the electric power supplied to the heated plate was increased gradually there was a gradual increase in the heat flux transferred to the fluid in the minichannel. That resulted in the onset of nucleate boiling and enhancement of heat transfer. The distribution of temperature on the smooth surface of the heated plate was measured using infrared thermography. Simultaneously, the flow pattern was observed on the other side of the minichannel (enhanced surface of the heated plate in contact with the fluid).

\section{Determination of the heat transfer coefficient}

Local values of the heat transfer coefficient $\alpha(x)$ were established using a one-dimensional approach. Two boiling regions, subcooled and saturated, were considered. The heat flow direction, which was perpendicular to the direction of the fluid flow in the minichannel, was taken into account and it was determined using the following equation [21]:

$$
\alpha(x)=q_{w} /\left(T_{p}\left(x, \delta_{p}\right)-T_{l}(x)-q_{w} \cdot \frac{\delta_{p}}{\lambda_{p}}\right)
$$

where $x$ - the distance from the minichannel inlet along the direction of the flow, $q_{w}$ - the heat transferred to the fluid in the minichannel (heat flux density), $T_{p}(x)-$ the plate temperature measured by infrared thermography, $T_{l}(x)=T_{f}(x)$ in the subcooled boiling region, $T_{f}(x)$ - the fluid temperature determined on the basis of the linear distribution of the fluid temperature along 
the length of the minichannel from the inlet to the outlet, $T_{l}(x)=T_{\text {sat }}(x)$ in the saturated boiling region, $T_{\text {sat }}(x)$ - the saturation temperature determined on the basis of the linear distribution of pressure along the length of the minichannel from the inlet to the outlet, $\lambda_{p}-$ the coefficient of thermal conductivity of the plate, $\delta_{p}-$ the plate thickness.

As assumed in [21], the heat transferred to the fluid in the minichannel $q_{w}$ is equal to the difference between the heat generated by the heated plate and the heat lost to the surroundings.

The temperature measurements by infrared thermography were performed for the central part of the heated plate, where there was no insulation and, consequently, the loss of heat to the surroundings was the greatest. The heat loss was reported to constitute $1.3 \%$ of the heat flux density [21].

\section{Results and analysis}

The measurements were recorded for the assumed heat flux supplied to the heated plate, under similar stable thermal and flow conditions. The experimental results pertain to the steady state (stationary condition). The analysis includes the data from the experiments performed for seven various angular positions of the test section with the minichannel and mass flow rate $Q_{m}=3 \cdot 10^{-3} \mathrm{~kg} \cdot \mathrm{s}^{-1}$. The minichannel was inclined at 0 , 30, 60, 90, 120, 150 and 180 degrees, see Fig. 2b. The results are presented graphically as the heat transfer coefficient versus the distance from the minichannel inlet obtained for two boiling regions: (the subcooled boiling region, Fig. 3 and the saturated boiling region, Fig. 4) and as boiling curves (Figs. 5-6).

Local heat transfer coefficients were determined using the one-dimensional method described in [21].

The boiling curves shown in Figs. 5-6 were constructed at seven inclination angles from ranges $0^{\circ} \div 90^{\circ}$ (Figs. 5a,c, 6a,c) and $120^{\circ} \div 180^{\circ}$ (Figs. 5b,d, $6 \mathrm{~b}, \mathrm{~d})$. The curves were plotted as the heat flux density against differences $T_{p}-T_{f}$ (Figs. 5a-b, 6a-b) and $T_{p}-T_{\text {sat }}$ (Figs. 5c-d, 6c-d) for two selected distances: 1/3 from the inlet $-0.06 \mathrm{~m}$ (Figs.5a-d) and 1/3 from the outlet $0.12 \mathrm{~m}$ (Figs. 6a-d).

During the experiments, boiling started and developed at higher heat fluxes when distilled water was used as the working fluid in the minichannel. This is related to different properties of the fluids and their boiling points, $56{ }^{\circ} \mathrm{C}$ for Fluorinert $\mathrm{FC}-72$ and $100{ }^{\circ} \mathrm{C}$ for water at atmospheric pressure.

Experimental parameters of the tested experimental series are presented in Tables 1 and 2 as representative data for the subcooled and saturated boiling regions.

In the subcooled boiling region (Fig. 3), heat transfer coefficients were relatively high compared with the results obtained with FC-72 as the working fluid $[9,10]$ but at substantially higher heat fluxes. The local heat transfer coefficient values increased with the distance from the minichannel inlet $(0.12 \mathrm{~m})$ to the outlet $\left(\begin{array}{ll}0.18 \mathrm{~m}\end{array}\right)$ and achieved maximum of about $10 \mathrm{~kW} \cdot\left(\mathrm{m}^{-2} \mathrm{~K}^{-1}\right)$ at the highest heat flux. The highest local heat transfer coefficients were achieved for orientation $0^{\circ}$ and $30^{\circ}$ for all heat fluxes analysed.

In the saturated boiling region (Fig. 4), local heat transfer coefficients decreased with the distance from the minichannel inlet. The local heat transfer coefficient values were comparison to values in the subcooled boiling region. The coefficients and their dependence on the distance from the minichannel inlet varied from those obtained in the experiments using FC-72 as the working fluid. The highest coefficients were recorded in the saturated boiling region (FC-72). With FC-72, local heat transfer coefficients were several times higher at the saturated boiling region in comparison to the values obtained in the subcooled boiling region. In the saturated boiling region the coefficient values were typically observed to decrease with the growing distance from the minichannel inlet [24-25]. The differences between the values obtained with distilled water and FC-72 Fluorinert are the result of different physical properties of the two fluids, such as wettability, viscosity and surface tension. The two-phase flow patterns observed during the experiments with water also varied considerably from those identified earlier for FC-72. Developed heated surfaces require proper selection of geometrical parameters for specific liquids. The study on pool boiling [17] indicates that smaller dimensions of cavities are suitable for liquids with lower surface tensions (as FC-72) at heat fluxes above $25 \mathrm{~kW} \cdot \mathrm{m}^{-2}$.

Table 1 Experimental parameters for the subcooled boiling region

\begin{tabular}{|c|c|c|c|c|}
\hline $\begin{array}{c}\text { Set of } \\
\text { heat } \\
\text { flux } \\
\text { (No.) }\end{array}$ & $\begin{array}{c}\text { Average } \\
\text { mass flux } \\
\left(\mathrm{kg} \mathrm{m}^{-2} \mathrm{~s}^{-1}\right)\end{array}$ & $\begin{array}{c}\text { Average } \\
\text { inlet } \\
\text { pressure } \\
p_{\text {in }} \\
(\mathrm{kPa})\end{array}$ & $\begin{array}{c}\text { Average } \\
\text { inlet liquid } \\
\text { subcooling } \\
\Delta T_{\text {sub }} \\
(\mathrm{K})\end{array}$ & $\begin{array}{c}\text { Heat } \\
\text { flux } \\
\text { density } \\
q_{w} \\
\left(\mathrm{kWm}^{-2}\right)\end{array}$ \\
\cline { 1 - 2 } 1 & 98 & 126 & 15 & 125 \\
\cline { 1 - 1 } 2 & & & & 135 \\
\cline { 1 - 1 } & & & & 145 \\
\cline { 1 - 1 } & & & & 155 \\
\hline
\end{tabular}

Table 2 Experimental parameters for the saturated boiling region

\begin{tabular}{|c|c|c|c|c|}
\hline $\begin{array}{l}\text { Set of } \\
\text { heat } \\
\text { flux } \\
\text { (No.) }\end{array}$ & $\begin{array}{c}\text { Average } \\
\text { mass flux } \\
G \\
\left(\mathrm{~kg} \mathrm{~m}^{-2} \mathrm{~s}^{-1}\right)\end{array}$ & $\begin{array}{c}\text { Average } \\
\text { inlet } \\
\text { pressure } \\
p_{\text {in }} \\
(\mathrm{kPa})\end{array}$ & $\begin{array}{c}\text { Average } \\
\text { inlet liquid } \\
\text { subcooling } \\
\Delta T_{\text {sub }} \\
\text { (K) }\end{array}$ & $\begin{array}{c}\text { Heat } \\
\text { flux } \\
\text { density } \\
q_{w} \\
\left(\mathrm{kWm}^{-2}\right)\end{array}$ \\
\hline 2 & \multirow[t]{4}{*}{98} & \multirow[t]{4}{*}{128} & \multirow[t]{4}{*}{14} & 135 \\
\hline 3 & & & & 145 \\
\hline 4 & & & & 155 \\
\hline 5 & & & & 165 \\
\hline
\end{tabular}



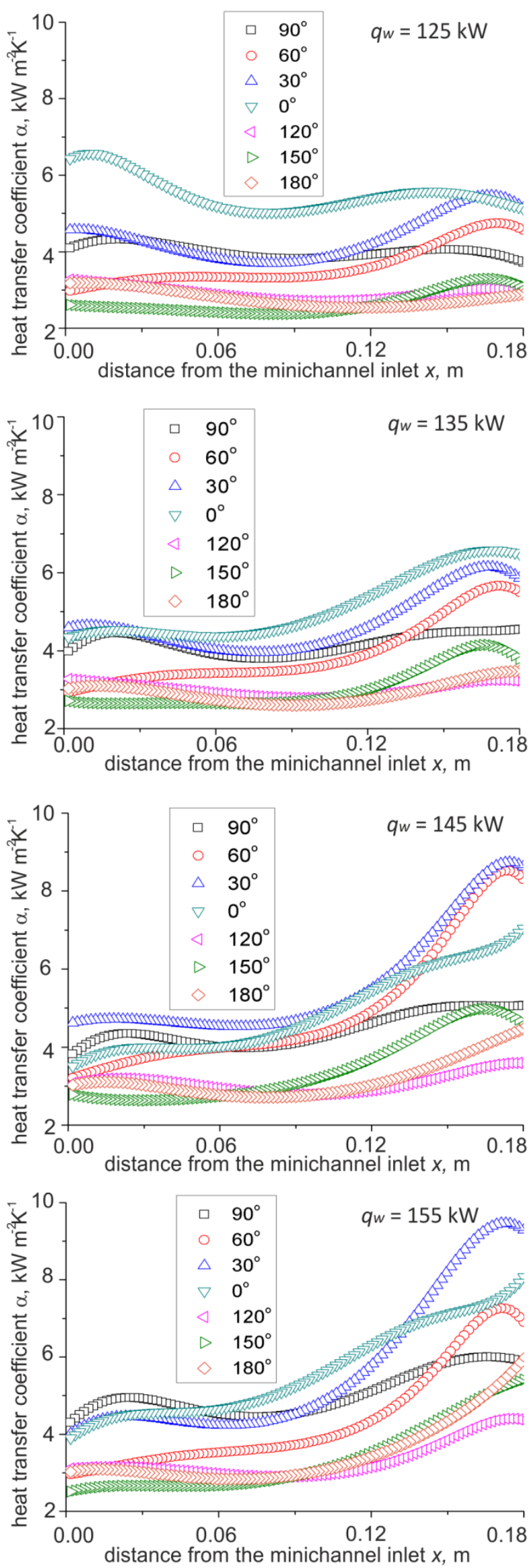

Fig. 3. Heat transfer coefficient vs. distance from the minichannel length obtained for the subcooled boiling region for all tested minichannel orientations and four heat fluxes.
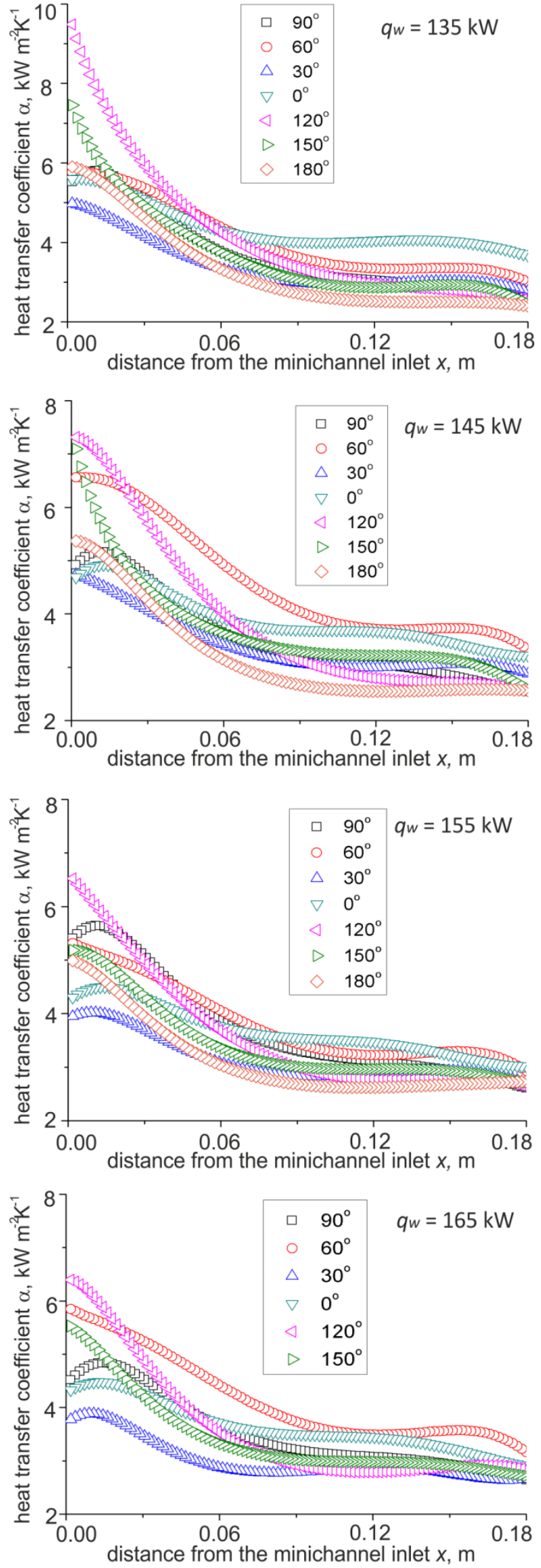

Fig. 4. Heat transfer coefficient vs. distance from the minichannel length obtained for the saturated boiling region for all tested minichannel orientations and four heat fluxes. 

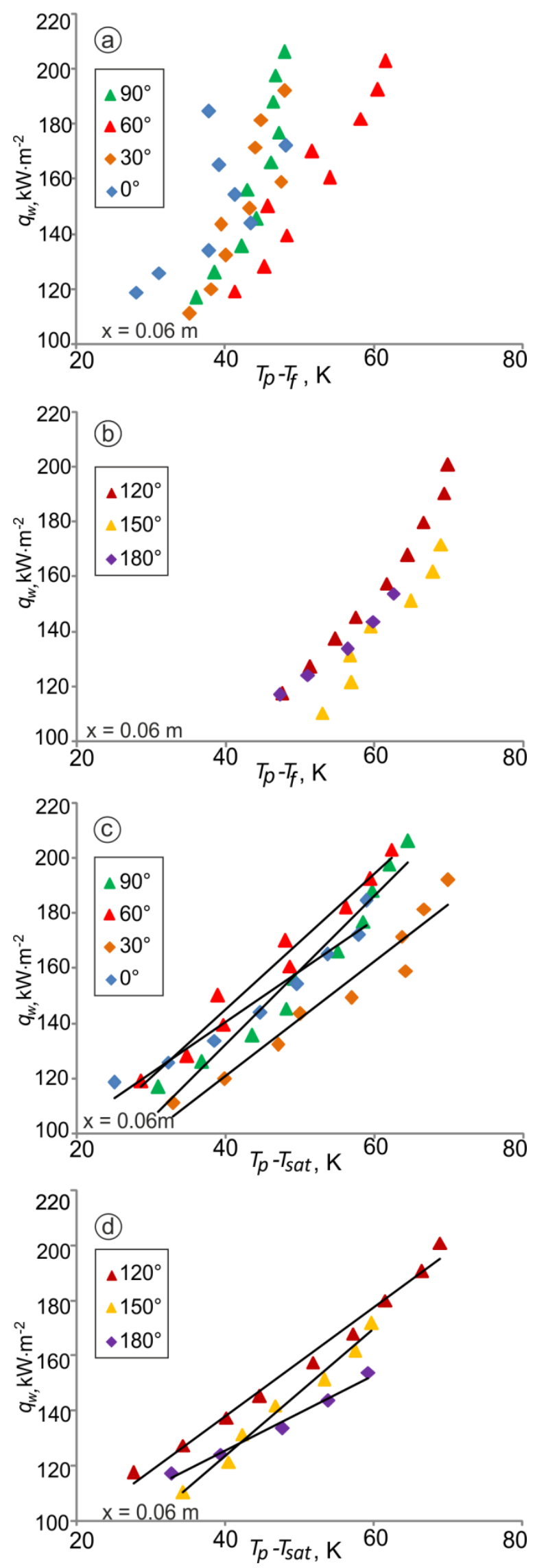

Fig. 5. Boiling curves for the $0.06 \mathrm{~m}$ distance from the minichannel inlet, orientation: a, c) $0^{\circ}-90^{\circ}$, b, d) $120^{\circ}-180^{\circ}$, $T_{p}$ - heated plate temperature, $T_{f}$ - bulk fluid temperature, $T_{\text {sat }}$ - fluid saturation temperature.
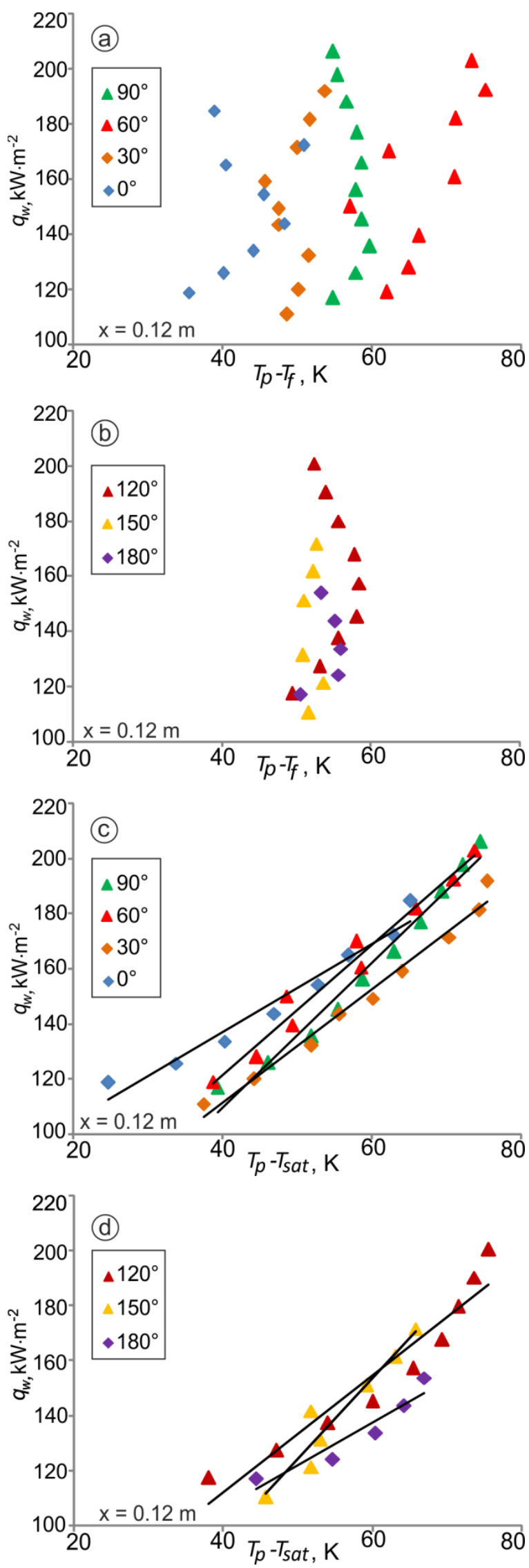

Fig. 6. Boiling curves for the $0.12 \mathrm{~m}$ distance from the minichannel inlet, orientation: a, c) $0^{\circ}-90^{\circ}$, b, d) $120^{\circ}-180^{\circ}$, $T_{p}$ - heated plate temperature, $T_{f}$ - bulk fluid temperature, $T_{\text {sat }}$ - fluid saturation temperature. 
As for the influence of the angular position of the minichannel on the value of heat transfer coefficient in the saturated boiling region, the results indicate that:

- the maximum values were achieved at orientation $120^{\circ}$ (Figs. 4 a-d), at the inlet of the minichannel.

- the lowest were obtained at orientation $30^{\circ}$ (Figs. $4 \mathrm{a}-\mathrm{d})$, at the inlet of the minichannel and at orientation $180^{\circ}$ (Figs. $4 \mathrm{a}-\mathrm{c}$ ), at about $1 / 3$ of the distance from the minichannel inlet.

- high values of the heat transfer coefficient were also recorded at orientation $60^{\circ}$ (Fig. $4 \mathrm{~b}, \mathrm{~d}$ ) and orientation $0^{\circ}$ at about inlet to $2 / 3$ of the distance from the minichannel inlet (Fig. 4a).

The arrangement of points on the boiling curves plotted vs. $T_{p}-T_{f}$ (Fig. 5a and Fig. 6a) shows the highest scatter and variability of the data obtained for four orientations: $0^{\circ}, 30^{\circ}, 60^{\circ}$ and $90^{\circ}$. The boiling curve at $60^{\circ}$ orientation was constructed for the highest $T_{p}-T_{f}$ difference. The curves for the remaining three orientations, i.e., $120^{\circ}, 150^{\circ}$ and $180^{\circ}$, were constructed for the highest difference $T_{p}-T_{f}$ and were similar. At orientations $0^{\circ} \div 90^{\circ}, T_{p}-T_{f}$ is mainly in the range from $20 \div 60 \mathrm{~K}$ (Fig. 5a) or $20 \div 80 \mathrm{~K}$ (Fig. 6a), whereas at $120^{\circ} \div 180^{\circ}$ in the range from $40 \div 80 \mathrm{~K}$ (Fig. 5b) or $40 \div 60 \mathrm{~K}$ (Fig. 6b).

Analysis of the boiling curves plotted vs. $T_{p}-T_{\text {sat }}$ (Figs. 5c-d and Figs. 6c-d) has a course close to linear and parallel for various inclination angles (the highest for orientation $120^{\circ}$ - Figs. 5d, 6d and orientation $60^{\circ}$ - Figs. 5c, 6c) and the heated surface superheat differences are substantial, with $T_{p}-T_{\text {sat }}$ of $77 \mathrm{~K}$ for the highest heat flux.

\section{Conclusions}

This paper discusses test results concerning flow boiling heat transfer in a minichannel with a surface modified by vibration-assisted laser texturing. Distilled water was used as the cooling fluid. Local values of the heat transfer coefficient were calculated using a onedimensional method. The analysis includes the data from the experiments performed for seven various angular positions of the test section with the minichannel. The minichannel was inclined at $0,30,60,90,120,150$ and $180^{\circ}$. The results are presented graphically as the heat transfer coefficient vs. the distance from the minichannel inlet obtained for two boiling regions (subcooled and saturated), and as boiling curves.

The highest local heat transfer coefficients were achieved for orientations $0^{\circ}$ and $30^{\circ}$ in the subcooled boiling region and orientations $60^{\circ}$ and $120^{\circ}$ in the saturated boiling region.

The boiling curves plotted vs. $T_{p}-T_{\text {sat }}$ has a course close to linear and parallel for various inclination angles and vs. $T_{p}-T_{f}$ shows the highest scatter and variability of the data obtained for four orientations: $0^{\circ}, 30^{\circ}, 60^{\circ}$ and $90^{\circ}$.

The data for water were compared with the findings reported for FC-72 to identify the influence of working fluid types on flow boiling heat transfer in minichannels with enhanced heated surface. The differences between the values of the heat transfer coefficient obtained in the experiments with distilled water and FC-72 Fluorinert resulted from different physical properties of these two fluids. The heated surface of the minichannel used in the experiments was enhanced, which led the initiation and development of the flow boiling process. The developed heated surfaces require proper selection of geometrical parameters for specific liquids to intensify heat transfer processes with a phase change.

\section{Acknowledgements}

The research reported herein was partly supported by a grant from the Polish National Science Centre (No. DEC-2013/09/B/ST8/02825).

\section{References}

1. K. H. Bang, K. K. Kim, S. K. Lee, B. W Lee, Int. J. Therm. Sci. 50 (3), 280-286 (2011)

2. H. T. Phan, N. Caney, P. Marty. S. Colasson, J. Gavillet, Appl. Therm. Eng. 31 (11-12), 1894-1905 (2011)

3. E. Sobierska, R. Kulenovic, R. Mertz, Int. J. Therm. Sci. 46, 1172-1181 (2007)

4. E. Sobierska, R. Kulenovic, R. Mertz, M. Groll, Exp. Therm. Fluid Sci. 31, 111-119 (2006)

5. F. Yang, X. Dai, Y. Peles, P. Cheng, J. Khan, Ch. Li, Int. J. Heat Mass Transf. 68, 703-715 (2014)

6. C. Konishi, Int. J. Heat Mass Transf. 92, 467-482 (2016)

7. C. Konishi, I. Mudawara, M.M. Hasan, Int. J. Heat Mass Transf. 65, 203-218 (2013)

8. J.S. Brower, J.F Klausner, Proc. HT-FED2004 Westin Charlotte \& Convection Center Charlotte, 1-6 (2004)

9. M. Piasecka, B. Maciejewska, Exp. Therm. Fluid Sci. 68, 459-467 (2015)

10. M. Piasecka, Int. J. Heat Mass Transf. 81, 114-121 (2015)

11. M. Piasecka, Int. J. Refrig. 56, 198-212 (2015)

12. W. Depczyński, S. Spadło, P. Młynarczyk, E. Ziach, P. Hepner, Proc. 24th Int. Conf. Metall. Mater. Met. 2015, Poland (2015)

13. B. Grabas, Exp. Therm. Fluid Sci. 74, 100-109 (2016)

14. B. Grabas, Exp. Therm. Fluid Sci. 68, 499-508 (2015)

15. N. Radek, K. Bartkowiak, Phys. Procedia, 499-505 (2011)

16. R. Pastuszko, Exp. Therm. Fluid Sci. 38, 149-164 (2012)

17. R. Pastuszko, R Kaniowski, EPJ Web Conf. 25, paper No. 02019 (2012)

18. R. Pastuszko, M. Piasecka, J. Physics Conf. Ser. 395, paper No. 012137 (2012)

19. T. Orzechowski, Exp. Therm. Fluid Sci. 31 (8), 947-955 (2007)

20. T. Orzechowski, A. Tyburczyk, ISI Master Journal List 87 (7), 48-51 (2011)

21. M. Piasecka, K. Strąk, B. Maciejewska, Heat Transf. Eng. 38 (3), 332-346 (2017) 
22. S. Hozejowska, R. Kaniowski, M.E. Poniewski, Int. J. Numer. Methods Heat Fluid Flow, 24, 811-824 (2014)

23. R. Kaniowski, M.E. Poniewski, Arch. Thermodyn. 34 (2), 3-22 (2012)

24. S. Blasiak, A. V. Zahorulko, Tribol. Int. 94, 126-137 (2016)

25. S. Blasiak, Int. J. Heat Mass Transf. 81, 90-102 (2015) 